\title{
A CONSTRUÇÃO DA IDENTIDADE FEMININA NO TEXTO DIGITAL TRANSMEDIA THE BIG BANG THEORY
}

\author{
FEMALE IDENTITY CONSTRUCTION IN DIGITAL TRANSMEDIA TEXT THE \\ BIG BANG THEORY
}

\section{Vanda de Sousa ${ }^{1}$}

Resumo: No contexto de uma análise working-in-progress, em torno do texto The Big Bang Theory, o presente momento reflexivo visa, especificamente, verificar se o conceito de gaze male (Mulvey, 2007), reconhecido na cinematografia tradicional (em particular na norteamericana), está (ou não) presente no texto digital transmedia em estudo. Começaremos por estabelecer $\mathrm{o}$ ato de fala como performativo da (auto)identidade (Benveniste, 1986); verificaremos a estabilidade do conceito nas narrativas digitais transmedia (Jenkins, 2003, 2011), assim, abrindo o espaço para a leitura das personagens femininas à luz dos estudos de género (Beauvoir, 2008; Butler, 2006; Foucault, 1970; Héritier, 2005; Rich, 1986, 2002; Vidal, 2005; Showalter, 2002). Nesse sentido, estabeleceremos o atual foco de reflexão no episódio 2 , da temporada 10, posto que convoca e discute o próprio conceito de personagem no contexto dos textos digitais transmedia. Tomando esse ponto de partida, será feita uma primeira interpretação da construção da identidade feminina, a qual se pretende tornar, futuramente, abrangente ao texto da série em causa, com vista a demonstrar (ou não) a nossa atual premissa.

Palavras - Chave: Humanidades Digitais; Textos Digitais Transmedia; Linguagem; Gaze Male; Estudos de Género.

Abstract: In the context of a working-in-progress analysis of The Big Bang Theory text, the
present reflective moment aims specifically to verify whether the male gaze concept (Mulvey,
2007), recognized in traditional cinematography (particularly in North- American), is (or is not)
present in the transmedia digital text under study. We begin by establishing the speech act as
performative of (self)identity (Benveniste, 1986); we will verify the stability of the concept in
transmedia digital narratives (Jenkins, 2003, 2011), thus opening the space for the reading of
the female characters in the light of gender studies (Beauvoir, 2008; Butler, 2006; Foucault,
1970; Héritier, 2005; Rich, 1986, 2002; Vidal, 2005; Showalter, 2002).In this sense, we will
establish the current focus of reflection in episode 2, season 10, since it summons and discusses
the concept of character in the context of transmedia digital texts. Taking this analise as a
starting point, it is our intention to develop a further interpretation concerning the feminine
identity construction, through out the serie, in order to consolidate (or not) our present premise.

\footnotetext{
${ }^{1}$ Professora Adjunta Convidada da ESCS - IPL (Escola Superior de Comunicação Social - Instituto Politécnico de Lisboa, investigadora do CISC - NOVA/FCSH - Universidade Nova de Lisboa, Faculdade de Ciências Sociais e Humanas). Integra o Conselho Editorial Internacional da EntreLetras. E-mail: vsousa@escs.ipl.pt
} 
Keywords: Digital Humanities; Digital Transmedia Text; language; Gaze Male; Gender Studies.

\section{Introdução}

A pergunta de partida reporta para a linguagem enquanto performativa da identidade. Esta mesma construção transvasa o texto narrativo linear (seja ele ficcional, poético, ensaístico ou diarístico) e afirma-se no texto fílmico, sob a forma de gaze male (MULVEY, 2007); face ao novo paradigma comunicacional e informacional, o que nos perguntamos é: nos textos digitais transmedia (não lineares) verifica-se (ou não), na linguagem, uma alteração do olhar masculino no exercício performativo da identidade feminina?

Isto é, chegados à era digital, promotora e facilitadora de uma globalização informacional e cultural (CASTELLS, 2001), a tendência da linguagem como performativa da identidade feminina sob o olhar masculino, mantém-se (in)alterada quando consideramos o texto digital transmedia não linear?

Seria expectável que, em contexto da Web 2.0 e da conciliação entre o audiovisual e a computação, propostas pelas Humanidades Digitais, a convergência cultural e, com ela, as narrativas digitais transmedia redefinissem, reorganizassem e reconfigurassem a questão da narrativa abrindo caminho a uma nova representação da identidade feminina. Para isso, vamos tomar como texto o episódio 2 da temporada 10 de The Big Bang Theory, no qual, justamente, é interrogada a linguagem como performativa da identidade. Baseados nesse texto, analisaremos as personagens femininas (residentes na série) e tomaremos a presente análise como ponto de partida para uma reflexão mais vasta em desenvolvimento (e a desenvolver), considerando diferentes abordagens ao texto em causa em trabalhos futuros.

\section{$1 \mathrm{O}$ ato de fala como ato performativo da identidade}

Mais do que à língua, o ato de fala pertence à linguagem, de cada vez que a língua é uma parte determinada e essencial da linguagem - ela é o produto da faculdade da linguagem, em si mesma um conjunto de convenções adotadas que que viabilizam o seu exercício no contexto de um corpo social (SAUSSURE, 1999, p. 34). Na língua verificamos a constância de imagens acústicas constantes que traduzem imagens constantes que, na escrita, correspondem às imagens verbais que aprendemos através do ato de fala. Assim, a linguagem é a faculdade de constituir uma língua - um sistema de sinais distintos que correspondem a ideias distintas (SAUSSURE, 1999, p. 36). Ou seja, um signo linguístico une não uma coisa e o seu nome, mas 
um conceito e a sua imagem acústica (SAUSSURE, 1999, p. 122). O indivíduo de per si é incapaz de fixar o valor de um signo cujo consentimento depende da comunidade. Por outras palavras, ao reconhecer-se a união entre um som e um conceito, urge considerá-lo no sistema (social, cultural) de que faz parte (SAUSSURE, 1999, p. 193). Neste sentido, a linguagem é em contexto (social, cultural).

Benveniste (1986) defende que não é possível pensar o homem antes da linguagem, da mesma forma que não é possível pensar o homem a "inventar" a linguagem. Isto é, a linguagem constitui o homem, construindo a subjetividade a cada momento que, pelo uso do pronome pessoal, um sujeito diz "eu" reportando-se, conscientemente, a uma interioridade que reconhece distinta da exterioridade do "tu" ("não-eu”).

Os pronomes pessoais estabelecem uma bipolaridade ôntica, ontológica (e filogenética ainda) que leva a que o ato de fala/linguagem se confirme como ato performativo da identidade (Benveniste, 1986). Pela linguagem, o homem narra a sua interioridade a uma exterioridade. O termo narrativa reporta para o termo latino narrare e para o indo-europeu gnares. Assim, narrar é conhecer-se a si mesmo em contexto, é conhecer-se imerso numa realidade a cada tempo e em cada lugar. $\mathrm{O}$ autoconhecimento e a autoconsciência que a narrativa implica impõem que esta seja construída a partir do "eu” (BEYNON, M., RUSS, S. MCCARTY, W., 2005) que se reconhece como um "não-eu" (BENVENISTE, 1986).

Ao narrar, o sujeito reporta-se a si e ao mundo que o rodeia, de cada vez que, narrar corresponde às necessidades de comunicar e compartilhar conhecimentos, cultura e valores. Por outras palavras, a narração põe em jogo personagens, enredo, elocução e pensamento (ARISTÓTELES, 1998). A sua condição de possibilidade assenta na suspensão tácita da descrença (COLERIDGE, 1817), tanto quando aceitamos que o narrado é real como quando, com consciência de que o narrado reporta ao imaginário, aceitamos tomá-lo como "real", desde que narrado no respeito pelo princípio da verosimilhança (ARISTÓTELES, 1998).

O advento das Novas Tecnologias Digitais da Informação e Comunicação, a par da expansão e vulgarização da Internet, em particular o wireless, conduziram-nos a um novo paradigma comunicacional que reconfigura, formal e tecnicamente, $\mathrm{o}$ ato narrativo que, todavia, na sua essência, não sofre alterações.

Hoje em dia, o desenvolvimento tecnológico libertou da linearidade o ato narrativo, criando o espaço para a leitura não-linear, ao mesmo tempo que estabeleceu a interatividade. $\mathrm{O}$ texto audiovisual (seja ele fílmico, televisivo ou multimédia) dispõe de tecnologias que, pelo 
agenciamento espacial e temporal, lhe permitem romper a linearidade. $\mathrm{O}$ usuário do ato narrativo é, atualmente, prosumer (TOFFLER, 1984). As narrativas digitais transmedia, possibilitam que o usuário abandone o seu tradicional lugar passivo (ouvinte/leitor/espectador) e se torne um usuário ativo.

O novo paradigma dos media define-se pela possibilidade de sobreposição de camadas diversificadas a par da interconexão (JENKINS, 2011). A narrativa transmedia desenvolve-se no seio do paradigma da convergência mediática e ambiente digital que determinam a forma, a produção, a difusão e a receção de produtos culturais (JENKINS, 2003). Os novos media libertam-se (e libertam-nos) da comunicação bidirecional. Se os antigos media promoviam o compartilhamento do espaço emocional, os novos media promovem o compartilhamento do espaço cognitivo (MANOVICH, 2001). Reportemo-nos à partilha de espaço emocional ou à partilha de espaço cognitivo, estamos sempre (e ainda) a reportarmo-nos ao indivíduo, à identidade de que o ato de fala se faz performativo.

Assim, no contexto do novo paradigma comunicacional, ressurge a necessidade de responder à questão: Como é construída a identidade feminina nas narrativas digitais transmedia?

\section{O Masculino da Frase}

Parece ser consensual que o momento de viragem na escrita feminina pode ser adjudicado ao modernismo, em particular, no romance. As mulheres deixam de escrever restritas às relações emocionais e passam a ousar os caminhos políticos, sociais, culturais, agora, num plano intelectual. O olhar que o feminino dirige ao mundo deixa de ser filtrado ora pelo olhar do pai, do irmão ou do marido. As mulheres passam a usar a escrita como forma de expressão da sua visão crítica da sociedade que as rodeia. Em termos woolfianos, é chegado o momento de serem quebradas as barreiras da doxa masculina (espaço ecoado pela herança platónica e platonizante da cultura ocidental) reclamando o reconhecimento da capacidade feminina de representar o mundo (WOOLF, 2000, p. 92).

Assim, o que se reclama é o próprio direito à palavra, à linguagem, a nomear o mundo no feminino desenhando as suas próprias cartografias e representações em cada espaço e a cada tempo, posto que, como Butler (2006) defende, o eu é constituído por um mundo social que não é resultado de uma escolha subjetiva e identitária. 
Para Derrida (1973), a história do pensamento ocidental, mais do que se sustentar quer no logocentrismo quer no fonocentrismo, encontra neste pressuposto axiomático a sua (in)formação que devém cosmovisão, no sentido em que se apresenta como uma estrutura através da qual nos posicionamos face (e no) mundo e estabelecemos o exercício da nossa expressão. Ou seja, estabelecida a dicotomia sujeito/objeto, esta abre o espaço ao egocentrismo humanista, característica marcante do pensamento liberal europeu, que coloca o sujeito masculino no epicentro do pensamento, tornando-o, assim, fonte, origem, ação e finalidade do próprio pensamento (DERRIDA, 1973, p. 299). Desta forma, a expressão crítica (seja ela escrita, falada ou pensada) sobre o real envolvente, no qual estamos imersos, verifica-se masculinizante.

Falar de ou sobre a mulher incorre no risco da assunção do feminino segundo uma lógica que o desconhece (IRIGARAY, 1977, p. 75). As categorias universais nas quais ancoram a oposição entre masculino e feminino e são, ainda, hierarquizadas dado que os valores presentes no pólo masculino são considerados como superiores aos que se fazem presentes ao pólo feminino (VIDAL, 2005, p. 67-68). Qualquer que seja a nomeação, a raiz da questão radica na diferença entre o mesmo e o outro (BEAUVOIR, 2008, p. 27-28), ou, se preferimos, respetivamente eu e tu (no contexto dos conceitos de Benveniste).

A diferença sexual não se reduz a um simples dado natural extralinguístico, essa diferença informa a língua, a linguagem, a cultura, de cada vez que o género gramatical feminino surge como o não masculino, gerando a exclusão do feminino na ordem gramatical linguística patriarcal (IRIGARAY, 1990, p. 22-23).

Quando começa a escrever, a mulher confronta-se com a dificuldade técnica da forma como a frase é (foi) criada pelos homens (WOOLF, 2000, p. 92). Começando por ser um lugar masculino, a escrita feminina recorda-se, a si mesma, como masculina: A frase é masculina! encontrar a sua própria forma é, para a escrita feminina, encontrar o feminino da frase, encontrar a desconstrução da formulação masculina (WOOLF, 2000, p. 92). Ser escrita no feminino significa a autenticidade da escrita que, sendo feminina não deve pretender-se masculina, nem tão pouco, deve pretender-se negação. A escrita feminina (seja a escrita substantivo) surge como lugar (tempo e espaço) do desenho de uma interioridade que (se) revela no fluxo de consciência (stream of consciousness) quer da autoria quer das personagens de cada vez que as personagens são o interposto lugar da autoria. 


\section{O Filme Como Texto}

O cinema é tornado linguagem, texto, de cada vez que "escreve" sob o estilo singular de cada autor (MARTIN, 1985). Assim, o cinema é, por direito, um texto (fílmico) porque opera uma linguagem, não com os objetos em si mesmos, mas antes, com a imagem dos objetos (Metz, 1980). As imagens desenvolvem, por si mesmas, um sistema de abstração, de discursão clarificando uma linguagem - uma lógica e uma razão (MORIN, 1997, p. 198-199). Não estamos face a uma realidade real, mas sim, estamos face a um enunciado (WOOLF, 2008), um sinal que verifica a ambiguidade de relação entre o real (objetivo) e o seu texto (imagem) sustentando a perceção intuitiva dos signos implícitos enquanto elementos de uma linguagem.

No texto fílmico, a imagem surge sugerindo, simbolizando, conforme à sua natureza simbólica (MORIN, 1997, p. 197), não sendo possível ignorar a continuidade que vai do símbolo ao sinal, já que todo o símbolo pressupõe um sinal, do mesmo modo que todo o simbolismo carrega um sinal (MORIN, 1997, p. 200). No texto fílmico continuamos regidos pelas coordenadas de(uma) linguagem enquanto faculdade de construir uma língua - um sistema de sinais distintos que correspondem a ideias distintas (SAUSSURE, 1999, p. 36).

O texto fílmico convoca uma sequência de imagens que o olhar observa, despertando, no cérebro, a consciência de que se assiste a algo que não é a realidade (WOOLF, 2008, p. 172). $\mathrm{O}$ texto fílmico distingue-se do texto escrito porque torna visível sem o recurso à palavra escrita (WOOLF, 2008, p. 175). A imagem não é o real, sugere o real, pelo que o seu ato representacional se inscreve no plano da narrativa (GARDIER, 2008, p. 20).

\section{O Gaze Male (O Olhar Masculino)}

Ser mulher é anterior à existência corpórea (BUTLER, 2006). O corpo é a capacidade de agir tanto quanto é o lugar em que as ações ocorrem. Há uma dimensão pública no corpo, construída enquanto fenómeno social, uma construção que é, antes demais, imaginária (SHOWALTER, 2002). Na esfera pública, o meu corpo não é o meu corpo, no sentido que o feminino é anterior ao corpo (BUTLER, 2006); na esfera pública, e dado que a linguagem é performativa da identidade, o meu corpo é um discurso (FOUCAULT, 1970).

A (bi)polaridade eu/tu (não-eu) que confirma o ato de linguagem como um ato comunicacional (de partilha, portanto), constrói (e constrói-se) sobre categorias binárias (HÉRITIER, 2005), as quais são geradas, desde logo, na oposição entre masculino e feminino. A raiz da questão está, então, na diferença entre o "eu" e o "outro" (não-eu) (BEAUVOIR, 
2008). De outra forma, a cultura surge como patriarcal por via de uma profunda marca da linguagem (IRIGARY, 1977). Acompanhando e acompanhado pelo desenvolvimento filogenético, o aparato tecnológico comunicacional tendeu a ser desenvolvido num ambiente patriarcal, ostracizando a mulher na sua própria pele, tornando-a uma função do discurso patriarcal (DOANE, 2000).

Os estudos fílmicos femininos emergiram dos estudos de cinema e têm como textos fundadores "Women and Film" (mais tarde, "Camera Obscura") e, posteriormente, "Screen" bem como os "Cahiers du Cinèma"; tomando posse dos conceitos pós-estruturalistas e da Escola de Frankfurt (KAPLAN, 2000, p. 5). Os estudos fílmicos femininos consideravam o contexto social e pretendiam esclarecer como era a categoria mulher usada como signo no contexto do próprio texto fílmico. Na década de setenta do século XX, a crítica clarificou que estavam a ser usadas representações da mulher que estavam embebidas na ideologia patriarcal dominante (KAPLAN, 2000, p. 119).

Mulvey (2007) coloca a questão do olhar masculino (gaze male); isto é, nos textos fílmicos, a identidade feminina é construída em acordo com o modo como a identidade masculina perspetiva (e se perspetiva face à) a identidade feminina. De outra forma, as personagens femininas tendem a ser circunscritas a uma posição social definida, como mulheres (COWIE, 1978). O que se pretende avaliar é se, em The Big Bang Theory, a construção das personagens femininas (Penny, Amy e Bernardette) é contraposta às personagens masculinas (Sheldon, Leonard, Howard, Rajesh), mantendo-se a presença de gaze male confirmado nas narrativas lineares.

O começo do episódio é particularmente elucidativo. Através do diálogo é lançada a proposta: somos personagens de ficção? Não somos reais? Somos ficção digital transmedia interativa? The Big Bang Theory é uma narrativa digital transmedia que permite às personagens masculinas (e apenas às personagens masculinas) que se questionem se são reais ou se são personagens de uma narrativa digital transmedia?

\section{The Big Bang Theory: Penny, Amy, Bernardette}

The Big Bang Theory (CBS, 2007), da autoria de Chuck Lorre e Bill Prady, é uma sitcom que toma o universo dos nerds como referência. O texto é multiplataforma, expandindo-se quer pelos novos quer pelos velhos media (Blogs, Fóruns, Merchandising, Jogos de Tabuleiro, Jogos Digitais Online, Banda Desenhada). 
A série segue a vida de um grupo de jovens cientistas que vivem na cidade de Pasadena, Califórnia. Como personagens residentes destacam-se: Sheldon Lee Cooper, Físico Teórico, Leonard Hofstadter, Físico Experimental, Howard Wolowitz, Engenheiro e o Astrofísico indiano Rajesh Koothrappali (também conhecido por Raj). Emergindo em torno das personagens masculinas, destacam-se as personagens femininas: Penny, é vizinha de Sheldon e de Leonard, nasceu e cresceu no Nebraska e sonha tornar-se uma atriz famosa; Penny subsiste do seu trabalho, como empregada de mesa, no restaurante Cheesecake Factory. Até à terceira temporada, Bernardette Rostenkowski é colega de Penny, no mesmo restaurante, ao mesmo tempo que termina o doutoramento em Microbiologia. A partir da terceira temporada, Bernardette surge como namorada de Howard; Amy Farrah Fowler é investigadora, doutorada em Biologia, pode ser considerada a versão feminina de Sheldon Lee Cooper.

Sublinhando que em The Big Bang Theory, as personagens femininas surgem a montante das masculinas, chama-se a atenção para a sequência de abertura do episódio 2 da décima temporada. Nesta sequência de abertura, a narrativa começa em casa de Sheldon e de Leonard. Sheldon pesquisa alguma informação no computador e comente com Leonard que, num fórum online, um jovem comenta que The Big Bang Theory é uma comédia de que estão à venda pequenas réplicas das personagens. Espantado com a informação, Leonard pergunta: Não somos reais?! Somos o produto da louca imaginação de um jovem que interage num fórum online?

Assim, é o próprio texto narrativo que convoca à reflexão em torno da linguagem enquanto performativa da identidade. No diálogo evocado, a identidade destacada é a masculina. Esta evocação pode ser lida como decorrente da ação dramática do episódio (já que as personagens principais da série são, efetivamente, os homens), mas afastando-nos, de uma abordagem criticista, permitimo-nos fazer confluir este diálogo com o pensamento de Benveniste (1986) e, genericamente, considerar a linguagem como performativa da identidade do eu como diferente do tu (não-eu). Assim, neste primeiro momento, extrapolamos o statement de abertura do episódio para as personagens femininas da série: Serão elas reais?! Ou serão o produto da louca imaginação de um jovem que interage num fórum online? $\mathrm{E}$, de uma maneira ou de outra, num caso ou no outro, a pergunta que nos fazemos é: De que identidade feminina a linguagem transmedia se faz performativa?

Fisicamente, Penny é alta, magra, sensual, loira e, sobretudo, constantemente revela a sua preocupação com a sua forma física quer fazendo ginástica em casa quer saindo para fazer 
jogging. Veste-se de forma algo provocante, frequentemente usa tops e calças justas ao corpo. A sua linguagem corporal é desenvolta, denota ter consciência da sua feminilidade que, sem dúvida, cultiva e usa como argumento quando o discurso não lhe basta. Vive sozinha, mas temos notícia dos seus múltiplos flirts mais ou menos consequentes. É autónoma no quotidiano. Vai às compras, trabalha até tarde, resolve os problemas domésticos. O seu carácter é moldado pela família disfuncional de que provém (irmão com historial de drogas e cadastro) e pelo estereótipo dos valores e cultura do Nebraska: o pai educou-a quase como se ela fosse um rapaz, não precisa de um homem para a defender! Ela mesma trata do assunto! Se Penny é assediada, só o pode ser pelos seus próprios fantasmas!

Penny tem o sonho de se tornar uma atriz famosa. Se começa por acreditar que isso acontece de acordo com o mito da atriz que é descoberta pro um importante realizador, acaba por investir num curso de teatro que não a levará muito mais longe, deixando-a no lugar de uma participação esporádica num filme de terceira categoria em que surge na personagem de um macaco mutante ou num pequeno comercial caricato. $\mathrm{O}$ seu sonho será o seu pesadelo até que o vença: abandonado, posto de lado, Penny aproveita a oportunidade de trabalhar na empresa farmacêutica em que Bernardette ocupa um lugar de prestígio.

A relação de Penny com o trabalho é, pois, desde logo marcada pelo padrão da loura incompetente! No Cheesecake Factory, Penny parece ser incapaz de tomar nota de um pedido de forma eficaz: ou porque troca os menus encomendados, ou porque demora na sua entrega, ou porque não aceita nem acata atitudes de preponderância por parte do núcleo das personagens masculinas que começam a frequentar o restaurante. Penny chega mesmo à impertinência. Se isso nos permite a leitura de uma certa independência, por outro lado, enfatiza o subtexto da sua incompetência. Nas suas participações como atriz, Penny mostra-se desolada! A sua figura esbelta surge primeiro oculta sob as vestes de um macaco e, depois, ridicularizada no comercial a um remédio para o hemorroidal!

Será na empresa farmacêutica que é permitido à personagem de Penny valorizar os seus atributos físicos, quando consegue construir uma relação positiva com o chefe direto - um homem de meia idade, de carácter difícil e conflituoso, mas que encontra pontos em comum com Penny: ambos temem a atitude de Bernardette em ambiente profissional! Ao longo do tempo, e depois de as próprias personagens femininas (Bernardette e Amy) terem enfatizado, na narrativa, receio pela incapacidade de Penny ser delegada de propaganda médica, a jovem obterá sucesso. 
Penny não tem estudos. Por oposição a todas as outras personagens, Penny é a loira que não estudou. De resto, a personagem retrata a sua passagem pelo liceu como um momento não de aprendizagem, mas de namoricos e brincadeiras que, por vezes, extravasam para situações de quase bullying. Ao interagir com o grupo, a falta de estudos revela-se mais um fantasma, de tal forma que chega mesmo a inscrever-se numa Universidade que vem a abandonar quer porque Leonard (então já seu namorado) se mostra preocupado com a incapacidade de Penny alcançar notas positivas quer porque, a certa altura da narrativa, Penny parece tomar consciência que o seu saber é diferente dos demais: ela tem fortes capacidades sociais, é a personificação do bom senso, conhecedora do carácter humano, é a ela quem cabe resolver todos os conflitos interpessoais, revelando um forte sentido de lealdade e amizade. Ao mesmo tempo, vamos poder perceber que ela é perspicaz e apta a deixar-se fascinar pelas novas tecnologias que, evidentemente, não domina.

Nem por isso, Penny é uma mulher de sonhos desfeitos. Isso mesmo está presente na forma como consome bebidas alcoólicas, de cada vez que se sente ameaçada ou insegura.

Penny fará par amoroso com Leonard que revelará grandes inseguranças quanto à possibilidade de ser amado por Penny. De estatura mais baixa, fisicamente o casal forma a metáfora dos seus sentimentos: uma mulher cobiçada, dominadora no relacionamento, pouco culta, mas com grandes capacidades sociais e uma líder nata, combinando estas características com a típica abordagem maternal à relação.

Amy é uma personagem intelectualmente privilegiada e atuando num campo científico de grande prestígio. Fisicamente, Amy é absolutamente desinteressante. Não parece reparar no que veste, não usa calças, as suas saias são sempre deselegantes e abaixo do joelho, contrapõe com Penny ao vestir-se, sistematicamente, de cores escuras e usando casacos de malha, camiseiros abotoados até ao colarinho, usa óculos, cabelos compridos descuidados, collants opacos. Amy parece querer demonstrar que a inteligência e a beleza são incompatíveis. Desajeitada, sem capacidade de interação social, chega a ser paradoxal que as suas principais pesquisas sejam no campo neurológico - tanto mais que a personagem é infantilizada através da constante afirmação da sua fixação na série infanto-juvenil Litle House on The Prairie, o que é confirmado pelos seus sonhos antiquados quase como se ela tivesse caído de uma outra geração.

Amy vive sozinha num apartamento que contrasta com o de Penny. Está sempre arrumado, Amy demonstra ser uma boa-de-casa, sabe cozinhar, é zelosa do seu espaço. 
Percebemos, ao longo da narrativa, que Amy foi alvo de bullying no seu tempo de estudante, que tem uma mãe dominadora que não acredita que a filha seja capaz de se apaixonar ou, de outra forma, que seja possível que alguém se apaixone por ela. E, contudo, a sua vida afetiva desperta quando conhece e se apaixona por Sheldon, vivendo ambos, ao contrário do par Penny/Leonard, um namoro altamente cerebral.

Tal como no par anterior, também aqui, o relacionamento amoroso é visto pelo prisma da mulher como figura maternal para o homem.

Fisicamente baixa, Bernardette convoca a personagem de Lolita do romance de Vladimir Nabokov (1955). Loira, de formas insinuantes, consciente da sua beleza, mas também da sua baixa estatura, Bernardette impõe-se pela forma assertiva e pelo tom de voz com que surge na ação. À semelhança de Amy, percebemos que também ela não tem as melhores recordações do liceu devido à sua evidente inteligência. É combativa, quase dominadora. Ao terminar o doutoramento e ir trabalhar para uma empresa farmacêutica, Bernardette usufruirá de um ordenado muito superior ao de Howard, o que será fonte de constantes conflitos no casal. Por contraponto aos outros dois casais, é Bernardette quem controla o dinheiro, ainda que caiba a Howard (com a preciosa ajuda de Raj) tomar conta da casa e dos filhos. De resto, Bernardette é a única das personagens femininas que não assumirá uma postura maternal em relação ao seu parceiro, ainda que Howard a veja como figura maternal já que lhe confere o poder que a mãe demonstrava ter sobre ele.

De todas as figuras femininas, Bernardette será a primeira a casar e a única a experimentar a gravidez e a maternidade, não sem que expresse de forma enfática o quanto a situação conflitua com a sua vida profissional. Para ela, estar grávida é um incómodo, um problema na progressão na carreira, desfeia-a fisicamente, obriga-a a permanecer em casa e, com o seu modo autoritário, incumbe Howard e o amigo Raj de tomarem conta, quer dela durante a gravidez, quer dos filhos.

\section{Conclusão: Penny! Penny! Penny!}

Assim, podemos considerar no núcleo de personagens residentes, três figuras femininas que permitem a sua leitura a nível físico, intelectual, doméstico, laboral e relacionamento amoroso, ajudando a uma construção travejada entre intelecto/realidade quotidiana social.

A nível intelectual o estereótipo da mulher loira é interpretado de duas formas: Penny que é loira e sem instrução e Bernardette que é loira e inteligente; Amy salvaguarda-se na 
mulher inteligente, mas em contrapartida condenada a um aspeto fisicamente pouco interessante e morena. Intelectualmente menos dotada e sem estudos, Penny é a figura feminina privilegiada a nível físico. Bernardette é inteligente, fisicamente interessante, mas destituída de sensibilidade feminina.

Cada uma dessas três figuras femininas tem tradução no modo como lidam com o espaço doméstico: Penny é despreocupada com a casa, preocupa-se com as compras, cuida da roupa, isto é, o seu esforço é colocado no modo como aparece aos olhos dos outros, a sua casa é obstruída com objetos desarrumados, desorganização, a seu favor tem o cozinhar; Amy recupera o estereótipo da dona-de-casa, a sua capacidade de cozinhar é reconhecida pelas restantes personagens, sabe receber (quase numa evocação da personagem woolfiana Clarissa Dalloway), a casa é um espaço pessoal e arrumado; Bernardette delega as tarefas domésticas e o cuidar dos filhos no marido que tem a ajuda do amigo Raj.

No que ao sucesso profissional diz respeito, Penny deixa-se embalar num sonho frustrante ao qual se agarra desesperadamente até que as amigas a convencem a aceitar um trabalho diferente, porém, em qualquer um dos trabalhos que lhe conhecemos, Penny mostrase sempre consciente de que é uma mulher atraente; Amy impõe-se no seu trabalho, mas despindo-se de feminilidade quase na assunção de que procura o reconhecimento intelectual, como se houvesse uma incompatibilidade entre este e a sensibilidade feminina; de resto, Bernardette confirmam exatamente este pressuposto de que, no ambiente profissional, a mulher deve "negar" os seus atributos físicos e a sua feminilidade. Se isso fosse possível ou postulável... A personagem extravasa a possibilidade ao introduzir a mesma postura no ambiente doméstico e na vida familiar.

Nos relacionamentos amorosos, as personagens surgem maternais no relacionamento que têm com os seus pares. Ainda que Bernardette seja autoritária para com Howard e ainda que seja mais evidente por parte da personagem masculina esse exercício maternal no relacionamento, na verdade, Bernardette replica o modo como a mãe de Howard lidava com ele. Assim, a limite, não será de excluir esse modo de ser mãe no relacionamento.

Penny surge como capaz de destruir corações, o sobressalto de Leornard que constantemente se interroga como pode ela amá-lo ou o medo de a perder, não se achando verdadeiramente merecedor de tal mulher, reposiciona-nos no estereótipo da mulher cuja beleza é perigosa. 
Amy confirma o discurso masculino de que a inteligência surge dissociada da beleza física e, por isso, só Sheldon (a mais intelectual das personagens masculinas) poderia apaixonarse por ela, de resto, a própria mãe de Amy desconfia da possibilidade da filha amar e ser amada. Bernardette concilia a beleza e a inteligência, mas fá-lo numa forma que de tão assertiva parece querer dizer-nos que esta não é uma boa combinação.

A construção da identidade feminina é, aqui e ainda, metamorfoseada pela forma obsessiva de Sheldon bater à porta da sua vizinha: Penny! Penny! Penny! Ecoando um imperativo obsessivo não muito distante do que reconhecemos na forma como as crianças tendem a chamar as mães.

Chegados aqui, parece ser possível concluir que em The Big Bang Theory, as personagens femininas, apesar de pertencentes a um novo paradigma comunicacional e surgirem em narrativas transmedia não lineares, não apresentam uma caracterização diferente das que as narrativas lineares propõem e, de acordo com as quais, a mulher é vista pelo olhar masculino, permanecendo a linguagem masculina ainda quando performativa da identidade feminina. A linguagem continua, pois, masculina.

\section{Referências}

ARISTÓTELES. A poética. Lisboa: Fundação Calouste Gulbenkian, 1998.

BEAUVOIR, S. O segundo sexo - os factos e os mitos. Lisboa: Quetzal Editores, 2008.

BENVENISTE, E. O homem na linguagem. Lisboa: Vega, 1986.

BEYNON, M., RUSS, S., MCCARTY, W. "Human computing - modelling with meaning", Literary and Linguistic Computing, June 2006. In https://www.researchgate.net/publication/31458408. Acesso em 17 set. 2018.

BUTLER. J. Défaire le genre. Paris: Éditions Amsterdam, 2006.

CASTELLS, M. A galáxia da Internet. Lisboa: Fundação Calouste Gulbenkian, 2001.

COUSINS, Mark A biografia do filme. Trad. Artur Ramos e Cládia Ramos. Lisboa: Plátano, 2005 .

COWIE. "Woman as Sign" (ed) Kaplan, Ann E. Feminism \& Film, Oxford, Oxford University Press, pp. 48-65, 1978.

DERRIDA, J. Gramatologia. São Paulo: Perspectiva, 1973.

DOANE, Mary Ann. "Woman's Stake: filming the female body (ed) Kaplan, Ann E. Feminism \& Film, Oxford: Oxford University Press, 2000, p. 86-99. 
FOUCAULT, M. L'ord du discurse. Paris: Gallimard, 1970.

GARDIES, René (org.). Compreender o cinema e as imagens. Lisboa: Texto \& Grafia, 2008.

HÉRITIER. "Construction d'un autre modèle du rapport des sexes. Peut-on le fonder sur l'absence de hiérarchie", dir. In. Héritier, F. hommes, femmes, la construction de la différence, Paris: Éditions Le Pommier, 2005, p. 168-183.

IRIGARAY, Luce. Ce sexe qui n'en est pás un. Paris: Les éditions de Minuit, 1977.

IRIGARAY, Luce. Je, Tu, Nous Pour Une Culture de la Différence, Paris: ed. Bernard Grasset, 1990.

JENKINS. Convergence culture: where old and New Media Collide. New York: New York University Press, 2003.

JENKINS. "Transmedia 202: Further Reflections", 2011. Disponível em : http://hneryjeckins.org/2011/08/defining_transmedia_further_re.html. Acesso em 10 set. 2018.

KAPLAN, E. A. "Is The gaze Male?” in Feminism \& film, ed. E. Ann Kaplan, Oxford University Press, Oxford, 2000.

MANOVICH. .The language of new media. Cambridge: MIT Press, 2001.

MARTIN, Marcel. A linguagem cinematográfica. Lisboa: ed. Dinalivro, 2005.

METZ, Christian. O significante imaginário - psicanálise e cinema. Lisboa: ed. Livros Horizonte, 1980.

MORIN, Edgar (1997) O Cinema ou o Homem Imaginário. Lisboa: ed. Relógio d'Água Editores;

MULVEY, L. Visual and other pleasures (language, discourse, society). Indiana: Indiana University Press, 2007.

RICH. "Notas para uma política de Localização" org Macedo, Ana Gabriela, Género, Identidade e Desejo. Lisboa: Cotovia, 2002.

$\mathrm{RICH}, \mathrm{B}$. R. The crisis of naming in feminist film criticism in Feminist Film Theory - A Reader, ed. Sue Thornham, New York: New York University Press, 2006.

RODOWICK, David N. The difficulty of difference in feminism \& film, ed. E. Ann Kaplan, Oxford: Oxford University Press, 2000.

SAUSSURE, F. Curso de Linguística Geral. Lisboa: Publicações Dom Quixote, Lisboa, 1999.

SHOWALTER, E. "A crítica feminista no deserto" In: MACEDO, Ana Gabriela (org.). Género, identidade e desejo, Lisboa: Cotovia: 2002. 
TOFFLER, A. A Terceira onda. Lisboa: Livros do Brasil, 1984.

Vidal, C. "Le cervereau a-t-il un sexe?" dir. Int. Héritier, francçoise, hommes, femmes, la construction de la différence. Paris: Éditions Le Pommier, 2005, p. 66-78;

WOOLF, Virginia (2000) A Room of One’s Own, ed. Peguin Books, London, 2000.

WOOLF, Virginia (2008) The Cinema in Selected Essays, ed. Oxford University Press, Oxford, 2008.

\section{Texto fílmico:}

The Big Bang Theory (CBS, 2007) authored by Chuck Lorre and Bill Prady (temporada 10, episódio 2).

Recebido em 10 de setembro de 2018. Aceito em 17 de setembro de 2018. 